Document downloaded from:

http://hdl.handle.net/10251/80987

This paper must be cited as:

Desantes Fernández, JM.; Bermúdez, V.; López, JJ.; López Pintor, D. (2016). A new method to predict high and low-temperature ignition delays under transient thermodynamic conditions and its experimental validation using a Rapid Compression-Expansion Machine. Energy Conversion and Management. 123:512-522. doi:10.1016/j.enconman.2016.06.051.

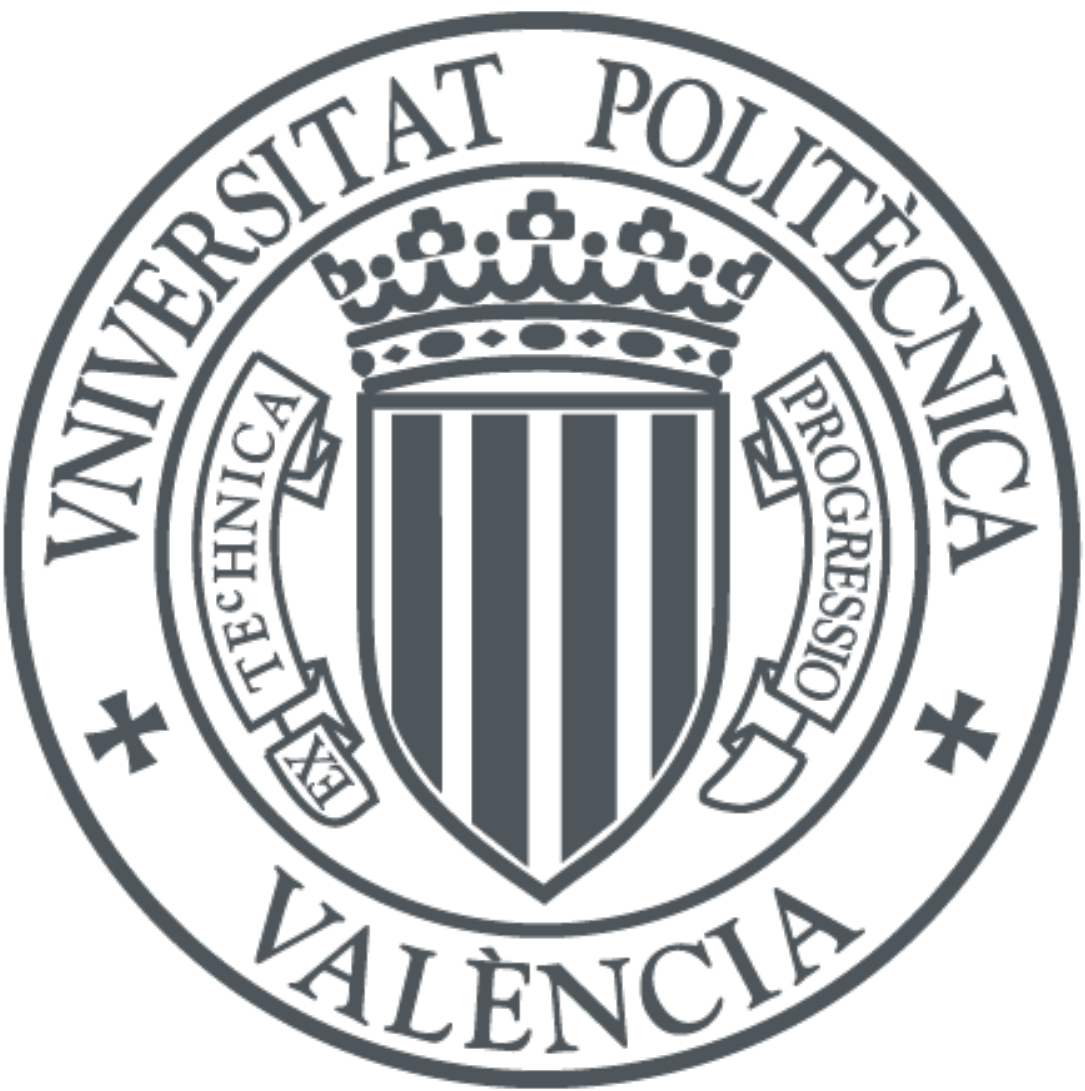

The final publication is available at

http://dx.doi.org/10.1016/j.enconman.2016.06.051

Copyright Elsevier

Additional Information 


\title{
A new method to predict high and low-temperature ignition delays under transient thermodynamic conditions and its experimental validation using a Rapid Compression-Expansion Machine
}

\author{
José M. Desantes ${ }^{\mathrm{a}}$, Vicente Bermúdez ${ }^{\mathrm{a}}$, J. Javier López ${ }^{\mathrm{a}, *}$, Darío \\ López-Pintor ${ }^{\mathrm{a}}$ \\ ${ }^{a}$ CMT-Motores Térmicos \\ Universitat Politècnica de València \\ Camino de Vera, s/n. 46022 Valencia, SPAIN
}

\begin{abstract}
A new procedure to predict both high-temperature stage and cool flames ignition delays under transient thermodynamic conditions has been developed in this paper. The results obtained have been compared with those obtained from the Livengood \& Wu integral method, as well as with other predictive methods and with direct chemical kinetic simulations and experimental data. All simulations have been performed with CHEMKIN, employing a detailed chemical kinetic mechanism. The simulations and predictions have been validated in the working range versus experimental results obtained from a Rapid Compression-Expansion Machine (RCEM). The study has been carried out with n-heptane and iso-octane, as diesel and gasoline fuel surrogates, under a wide range of initial temperatures (from $358 K$ to $458 K$ ), initial pressures (0.14MPa and 0.17MPa), compression ratios (15 and 17), EGR rates (from
\end{abstract}

\footnotetext{
${ }^{*}$ Corresponding author

Tel: +34963879 232. Fax: +34963877 659. E-mail: jolosan3@mot.upv.es
} 
$0 \%$ to $50 \%$ ) and equivalence ratios (from 0.3 to 0.8 ). The experimental results show good agreement with the direct chemical kinetic simulations and with the new predictive method proposed. In fact, the mean relative deviation between experiments and simulations is equal to $1.719 \%$ for n-heptane and equal to $1.504 \%$ for iso-octane. Besides, the new method has shown good predictive capability not only for the high-temperature stage of the process but also for cool flames, being the mean relative deviation versus the experimental data lower than $2.900 \%$. Better predictions of the ignition delay have been obtained with the new procedure than the ones obtained with the classic Livengood \& Wu expression, especially in those cases showing a two-stage ignition pattern.

Keywords: RCEM, ignition delay, autoignition modeling, fuels, chemical processes

\section{1. Introduction, justification and objective}

2 Advanced combustion modes based on the autoignition of a premixed 3 mixture with a certain degree of homogeneity, such as Homogeneous Charge 4 Compression Ignition (HCCI), Premixed Charge Compression Ignition (PCCI), 5 Reactivity Controlled Compression Ignition (RCCI) and others, have been 6 studied for the simultaneous reduction of soot and $\mathrm{NO}_{x}$ [1]. Their working 7 principle is based on Low Temperature Combustion (LTC) by avoiding the 8 soot and $\mathrm{NO}_{x}$ formation peninsulas, which can be seen in equivalence ratio 9 - temperature diagrams [2] and their effectiveness has been widely proved 10 in previous studies $[3,4]$. These modes show virtually zero emissions of 11 soot and $\mathrm{NO}_{x}$, but high emissions of unburned hydrocarbons (UHC) and 
carbon monoxide $(\mathrm{CO})$ that can be easily eliminated with well-known aftertreatment techniques. The lack of control over the autoignition process and over the heat release rate are the main challenge to implement these new combustion strategies in commercial reciprocating internal combustion engines [5].

Ignition is controlled by the chemical kinetics of the charge in these new combustion modes [6]. This control entails higher complexity because of the absence of an explicit ignition-controlling event, such as a spark or an injection process when very reactive conditions are reached in the combustion chamber (near top dead center). The reactivity of the mixture can be modified by adjusting the engine operating parameters, such as the Exhaust Gas Recirculation (EGR) rate and the inlet temperature. Therefore, improving the capability of predicting the autoignition is mandatory to properly modify the operating conditions of the engine and to control the heat release.

The autoignition event can be reasonably well predicted by using advanced CFD codes with detailed chemistry. However, the required computing time is too long to be solved in real time. Simple numerical methods with very short computing time are the only ones that can be implemented in an engine control unit. If these low computing time methods have enough accuracy to properly predict ignition delays, the control of the engine can be improved since decisions in real time can be taken.

Moreover, the use of detailed chemical kinetic mechanisms coupled with CFD codes is limited by the physical discretization of the domain. The computational cost of solving detailed chemistry in cases with a high number of cells could be unacceptable, imposing the use of simplified mechanisms. The 
total computing time can be reduced by implementing predictive numerical methods to determine the ignition delay instead of solving the involved reaction rates.

The Livengood \& Wu hypothesis [7], also known as the Livengood \& Wu integral method, allows to obtain ignition delays of processes under transient conditions of temperature and pressure by using the ignition characteristics under constant thermodynamic conditions, which are much easier to obtain both experimentally and by simulation. The expression proposed by these authors is the following:

$$
\int_{0}^{t_{i}} \frac{1}{\tau} d t=1
$$

where $t_{i}$ is the ignition delay of the process and $\tau$ is the ignition delay under constant conditions of pressure and temperature for the successive thermodynamic states.

The Livengood \& Wu integral assumes that the autoignition happens when a critical concentration of chain carriers is reached, being this critical concentration constant with pressure and temperature for a given air-fuel mixture. Besides, the oxidation process during the ignition delay is described by a single zero-order global reaction and, therefore, the reaction rate does not depend on time under constant thermodynamic conditions. The negative temperature coefficient (NTC) behavior cannot be correctly modeled under these hypotheses.

This integral has been traditionally enunciated as a method to predict knock in SI-engines [8]. However, it has been extended to CI-engines as a way to predict the ignition delay of homogeneous air-fuel mixtures as the 
ones used in HCCI combustion modes [9]. Several authors such as Ohyama [10], Rausen et al. [11], Choi et al. [12] and Hillion et al. [13] studied the implementation of the Livengood \& Wu integral in an engine control unit. These authors used the integral method to predict the start of combustion under HCCI conditions. This method can be combined with other simple models to obtain global parameters of the combustion process allowing the control of the engine in real time.

The integral method has been used in several CFD studies as the model to predict the autoignition delay. For example, Imamori et al. [14] coupled the Livengood \& Wu integral with Star-CD and KIVA 3 to improve the performance of a low speed two-stroke diesel engine. And Li et al. [15] linked the integral method with the CFD code VECTIS to study the effects of heterogeneities on a two-stroke HCCI engine fueled with gasoline.

The validity of the Livengood \& Wu integral when a two-stage ignition occurs has been wondered by several authors [16]. The integral method is not able to accurately predict the ignition delay because it is based on a single global reaction mechanism that ignores the cool flames. Some of these authors, as Liang and Reitz [17] or Edenhofer et al. [18], show the need to create simple algorithms, but more sophisticated than the integral method, to characterize the autoignition at low temperatures without using any chemical kinetic mechanism, since the integral method has great interest for the prediction of autoignition due to its simplicity and low computational cost. However, few alternatives to the Livengood \& Wu integral can be found in the literature.

Hernandez et al. [19] analyzed the validity of the Livengood \& Wu in- 
tegral by simulations performed with CHEMKIN for several fuels and with various chemical kinetics mechanisms. They proved that the predictions of the method are accurate if the fuel do not show a two-stage ignition pattern. These authors also proposed two different alternatives, one with better and another with worse results than the integral method. However, most of the alternatives proposed to improve the integral method are based on the method itself or assume the same hypotheses, which are too simplified.

Desantes et al. [20, 21] have proposed two different methods based on the Glassman's model to predict ignition delays referred to a critical concentration of chain carriers, which are previous works related to the current one. The hypothesis of constant critical concentration is avoided in both methods, whereas one of them also avoids the description of the autoignition process by a single zero-order global reaction. However, since the ignition delay is defined as the time when a critical concentration of chain carriers is reached, only ignition delays referred to critical concentrations can be predicted accurately. Therefore, the high exothermic phase of the ignition cannot be obtained, since the critical concentration occurs in a previous stage, as will be shown later in section 2 .

Numerical expressions based on more sophisticated autoignition models are needed in order to extend the range of validity of the methods. Moreover, both exothermic stages should be predicted in the case of fuels that show twostage ignition: cool flames and high-exothermic heat release. The validity of a possible procedure to determine both ignition delays under transient conditions is intended to be solved in this work. The study has been done with n-heptane and iso-octane, the reactivities of which are very similar to 
diesel fuel and gasoline, respectively. Despite the fact that more sophisticated surrogate fuels for diesel can be found in the literature, n-heptane and isooctane were chosen because extended and fully validated chemical kinetic mechanisms are available for both. Moreover, they are primary reference fuels (PRFs) employed to define the octane number reference scale, and they are widely used in the literature as diesel fuel and gasoline surrogates under engine conditions [22].

Simulations have been performed with the software of chemical simulation CHEMKIN. This software, which is developed by Reaction Design (ANSYS), is consolidated in the world of engineering investigations, and the chemical kinetics mechanisms of several hydrocarbons are perfectly defined to be used with it. Finally, the numerical results are validated experimentally using a Rapid Compression-Expansion Machine (RCEM).

The structure of the paper is the following: first, the theoretical development of a new expression to predict ignition delays under transient conditions is explained. Then, the experimental facilities involved in the study are presented. Afterwards, the methodological approach is described, including the experimental methods, the chemical kinetic simulations and the parametric study performed. Thereafter, the new method is validated with the experimental results and its predictive ability is compared with the chemical kinetic simulations and with other predictive methods. Finally, the conclusions of this study are shown. 


\section{Theoretical development of a new predictive method for ignition delays}

A new method to predict the ignition delay under transient thermodynamic conditions is obtained starting from the integral method proposed by Desantes et al. [21]. This new procedure intends to be able to predict not only the ignition delay referred to cool flames but also the ignition delay referred to the high-temperature exothermic stage of the process. Models based on a critical concentration of chain carriers are not able to accurately predict exothermic stages, since the critical concentration of chain carriers is reached before the sudden heat release rate. Thus, alternative procedures should be proposed, since exothermic stages are the only ones that can be easily measured experimentally.

In this section, two different theoretical developments are described. On the one hand, a predictive method for cool flames is explained. This method is based on the accumulation of chain carriers up to reach a maximum of concentration, which should occur at the same time than cool flames. $\mathrm{HO}_{2}$ is selected as chain carrier since it seems to be a good tracer of such phenomenon. Thus, $\mathrm{CC}=\mathrm{HO}_{2}$, where $\mathrm{CC}$ represents the chain carriers. On the other hand, a complementary predictive method for the high-temperature stage of the combustion process is developed. This method is based on the consumption of chain carriers from the critical concentration, therefore, it is a consecutive method to the one used for the accumulation of chain carriers. The selected chain carrier should be completely consumed when the sudden heat release occurs. Thus, $\mathrm{CC}=\mathrm{CH}_{2} \mathrm{O}$ for this second method. Three different ignition delays are defined in the following paragraphs: 
- $\tau_{1}$ is the ignition delay under constant thermodynamic conditions referred to the maximum pressure rise caused by cool flames.

- $\tau_{2}$ is the ignition delay under constant thermodynamic conditions referred to the maximum pressure rise caused by the high-temperature stage of the combustion process.

- $\tau_{C C}$ is the ignition delay under constant thermodynamic conditions referred to the critical concentration of chain carriers. Different species are proposed as chain carrier depending on the stage of the ignition to be predicted: $\mathrm{CC}=\mathrm{HO}_{2}$ for cool flames and $\mathrm{CC}=\mathrm{CH}_{2} \mathrm{O}$ for the high-temperature stage of the process.

\subsection{Prediction of cool flames}

As it is explained in detail in [21], assuming that during the ignition delay the termination reactions are not very important, since $\left[\mathrm{O}_{2}\right]>>[\mathrm{CC}]$ and $[F]>>[C C]$ (where $F$ represents the fuel), and considering an air-fuel mixture under constant conditions of temperature and pressure, the following expression for the evolution of the concentration of chain carriers can be obtained:

$$
[C C]=[C C]_{\max } \frac{t}{\tau_{C C}}
$$

where $[C C]_{\max }$ represents the critical concentration of chain carriers (maximum concentration of chain carriers, which defines the ignition time).

If a process under transient conditions of pressure and temperature is discretized as a series of thermodynamic states that remain constant for a 
time $d t$, the ignition time referred to a critical concentration of chain carriers can be obtained as follows:

$$
1=\frac{1}{[C C]_{\max , t_{i, C C}}} \int_{0}^{t_{i, C C}} \frac{[C C]_{\max }}{\tau_{C C}} d t
$$

where $t_{i, C C}$ is the ignition delay of the process referred to a maximum concentration of chain carriers and $\tau_{C C}$ and $[C C]_{\max }$ are the ignition delay referred to a maximum of chain carriers and the critical concentration of chain carriers, respectively, under constant conditions of pressure and temperature for the successive thermodynamic states.

The theoretical development for the obtention of Eq. 3 is described in detail in [21]. It should be noted that if the critical concentration of chain carriers is considered as a constant, Eq. 3 results in the Livengood \& Wu integral.

Despite the fact that Eq. 3 represents a method to predict ignition delays, only times of ignition referred to a critical concentration of chain carriers can be obtained. Therefore, the high exothermic stage of the process cannot be predicted, since the maximum heat realease rate occurs always after reaching the critical concentration of chain carriers. However, as can be seen in Fig. 1, a maximum in concentration of $\mathrm{HO}_{2}$ is reached at the same time where the maximum pressure rise rate of cool flames occurs. Therefore, the cool flames time can be predicted by taking into account $\mathrm{HO}_{2}$ as chain carrier and $\mathrm{HO}_{2}$ was selected as a good tracer of this phenomenon.

Finally, a schematic of Eq. 3 can be seen in Fig. 1. The accumulation behavior of $\mathrm{HO}_{2}$ is modeled by the accumulated area of Eq. 3, by using the $\tau_{C C}$ and $[C C]_{\max }$ functions related with this species. Once the value of 1 

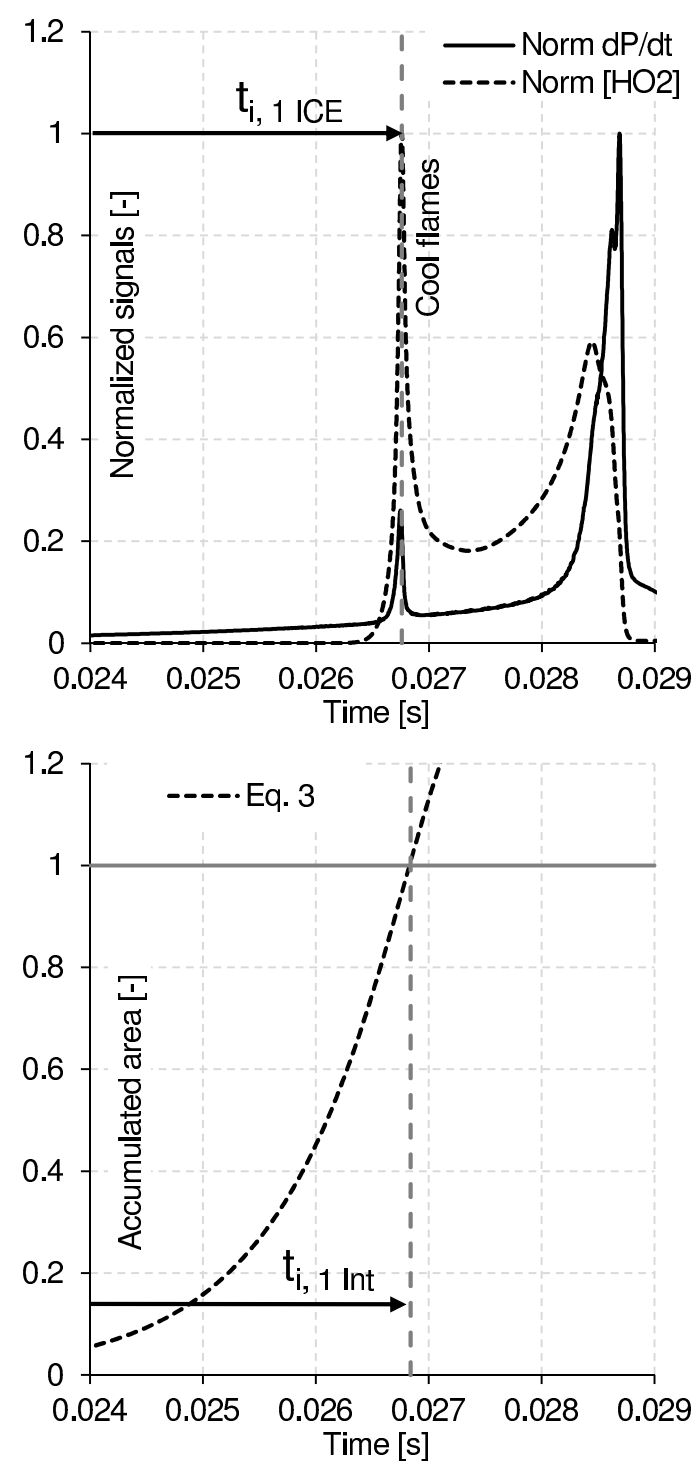

Figure 1: Accumulated area of Eq. 3 compared to normalized concentration of $\mathrm{HO}_{2}$ and normalized pressure rise rate, both obtained from CHEMKIN for $\mathrm{T}_{i}=408 \mathrm{~K}$, $\mathrm{P}_{i}=0.14 M P a, C R=15, \mathrm{X}_{\mathrm{O}_{2}}=0.147, F r=0.4$, n-heptane. 
is reached, the time at which the maximum concentration of $\mathrm{HO}_{2}$ occurs is predicted and, therefore, the ignition delay referred to cool flames is obtained.

\subsection{Prediction of the high-temperature stage}

The maximum heat release rate occurs when all the chain carriers are consumed. From a theoretical point of view, the heat release can be assumed as a sudden event. Therefore, considering an air-fuel mixture under constant thermodynamic conditions, the temperature and pressure conditions from the maximum concentration of chain carriers up to their disappearance can be assumed as invariants. Thus, and as it is explained in more detail in Appendix A, the evolution of the consumption of chain carriers can be obtained as:

$$
[C C]=[C C]_{\max } \frac{\tau_{2}-t}{\tau_{2}-\tau_{C C}}
$$

where $\tau_{2}$ represents the ignition delay referred to the maximum heat release rate.

Discretizing the process under transient conditions of pressure and temperature in a series of thermodynamic states that remain constant for a time $d t$, the ignition time referred to the high exothermic stage of the combustion can be obtained as follows:

$$
1=\frac{1}{[C C]_{\max , t_{i, C C}}} \int_{t_{i, C C}}^{t_{i, 2}} \frac{[C C]_{\max }}{\tau_{2}-\tau_{C C}} d t
$$

where $\tau_{C C}, \tau_{2}$ and $[C C]_{\max }$ are respectively the ignition delay referred to a maximum of chain carriers, the ignition delay referred to the high exothermic 
stage and the critical concentration of chain carriers under constant conditions of pressure and temperature for the successive thermodynamic states.

A schematic of this new procedure is shown in Fig. 2. $\mathrm{CH}_{2} \mathrm{O}$ is selected as chain carrier, since formaldehyde is widely recognized as an autoignition tracer [23]. The time at which the maximum concentration of $\mathrm{CH}_{2} \mathrm{O}$ is reached can be predicted by using Eq. 3, which accumulated area represents the accumulation behavior of this chain carrier. Then, the consumption of $\mathrm{CH}_{2} \mathrm{O}$ is modeled by the accumulated area of Eq. 5, by using the $\tau_{C C}$ and $[C C]_{\max }$ functions related with this species. It should be noted that the decomposition of chain carriers starts once the value of 1 is reached in Eq. 3 (once the maximum concentration of chain carriers is reached). When the accumulated area of Eq. 5 is equal to 1, the time at which all $\mathrm{CH}_{2} \mathrm{O}$ is consumed is predicted and, therefore, the ignition delay referred to the high-temperature stage is obtained.

The combination of Eq. 3 and Eq. 5 allows the prediction of the time of ignition referred to a maximum heat release rate (or pressure rise rate) under variable thermodynamic conditions, which is a parameter easily measurable in experimental facilities. It should be noted that if the fuel does not present a two-stage ignition, $\tau_{C C}$ and $\tau_{2}$ are virtually the same, and the ignition delays predicted for both integrals, $t_{i, C C}$ and $t_{i, 2}$, are also virtually the same. A more detailed explanation about this theoretical development can be found in Appendix A. 

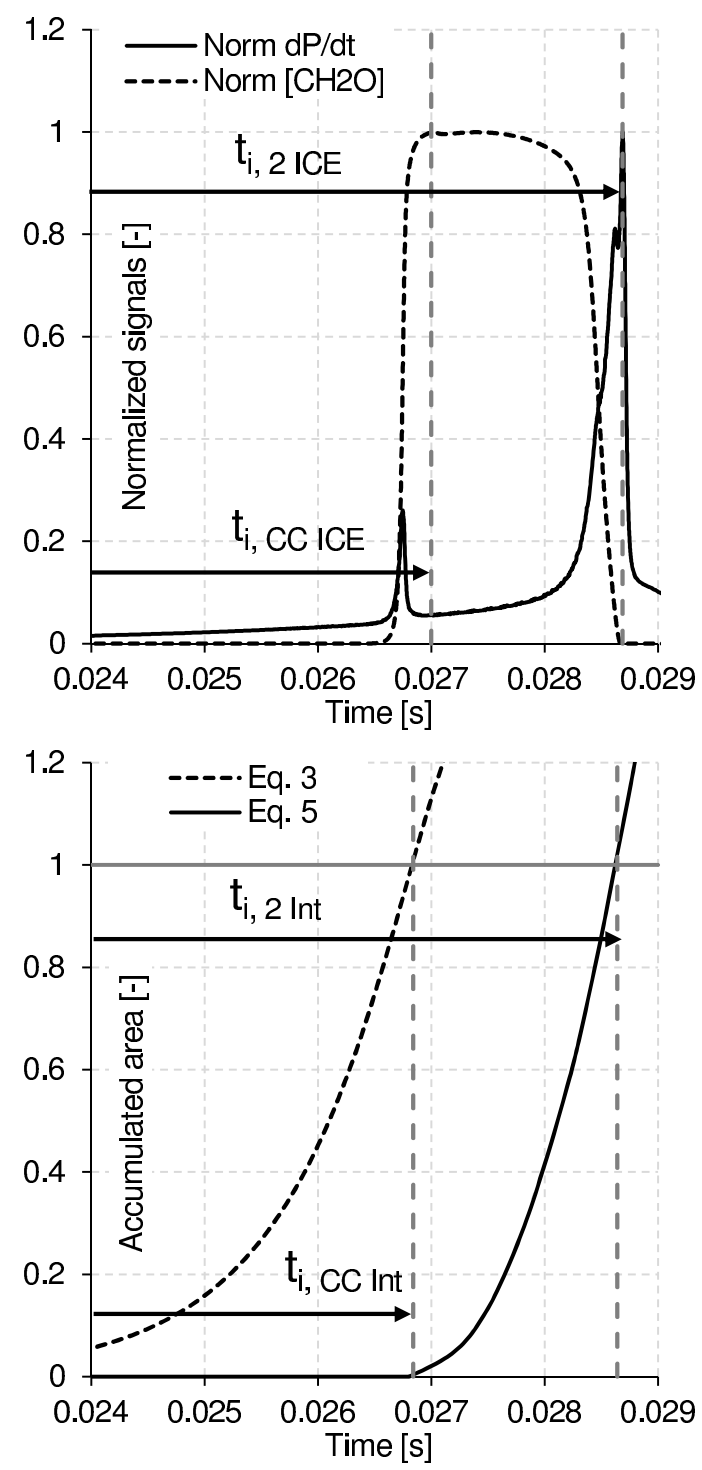

Figure 2: Accumulated area of Eq. 3 and Eq. 5 compared to the concentration of chain carriers $\left(\mathrm{CH}_{2} \mathrm{O}\right)$ and the pressure rise rate. $\mathrm{T}_{i}=408 \mathrm{~K}, \mathrm{P}_{i}=0.14 \mathrm{MPa}, \mathrm{CR}=15, \mathrm{X}_{\mathrm{O}_{2}}=0.147$, $F r=0.4$, n-heptane. 


\section{Materials and methods}

The accuracy of the new method to predict ignition delays was analyzed by comparison with the results of a parametric study performed in a RCEM following this methodology: for a certain case, the evolutions of both the in-cylinder temperature and pressure are experimentally obtained under motoring conditions. Then, the ignition delay, $\tau$, and the critical concentration, $[C C]_{\max }$, are obtained for each thermodynamic state by simulation in a perfectly stirred reactor. The ignition delay under transient conditions is then predicted by using the new procedure proposed in this paper and the Livengood \& Wu integral method. Besides, the ignition delay under transient conditions is obtained experimentally and it is also calculated by simulating it in an internal combustion engine reactor (direct chemical simulation) solving the detailed chemical kinetics mechanism. Finally, the predicted ignition delays and the values obtained from the direct chemical simulations are compared directly with the experimental results.

\section{1. $R C E M$}

A RCEM is an experimental facility widely used in autoignition studies due to its capability to reproduce engine conditions [24]. It can replicate reasonably well the combustion process of reciprocating engines with fully controlled initial and boundary conditions and avoiding the complexities associated to engines [25].

Different compression ratios can be reached in the RCEM by varying the stroke and the clearance volume. An axial optical access is available [26] and the compression velocity can be varied in order to simulate the effect of 


\begin{tabular}{|l|l|}
\hline 1 & Pushing piston \\
\hline 2 & Driver piston \\
\hline 3 & Displacement piston \\
\hline 4 & Air piston \\
\hline 5 & Combustion chamber \\
\hline
\end{tabular}

\begin{tabular}{|l|l|}
4 & Air piston \\
\hline 5 & Combustion chamber \\
\hline
\end{tabular}

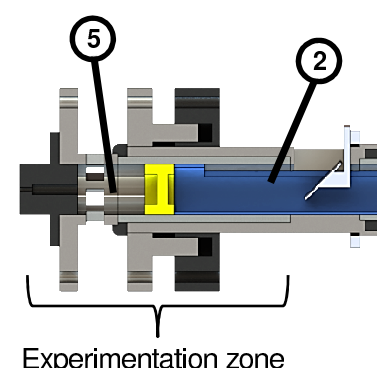

Experimentation zone

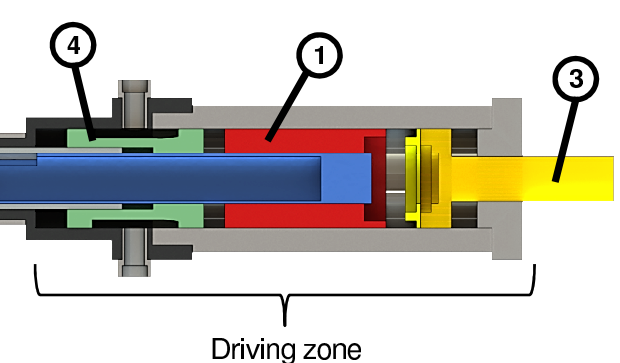

Driving zone

Figure 3: Rapid Compression Expansion Machine schematic.

different engine speeds. In a RCEM, part of the expansion stroke of the piston can be also analyzed, and most of the engine parameters can be calculated, such as the heat release rate or the combustion efficiency. In this facility both homogeneous and heterogeneous (direct injection) mixtures can be tested, as well as new combustion modes such as the dual fuel technology [27] or LTC $[28]$.

A schematic of the RCEM is shown in Figure 3. The RCEM is pneumatically driven and its pistons are hydraulically coupled. The machine can be divided in two different zones: the experimentation zone and the driving zone. The experimentation zone is composed by the combustion chamber, while the driving zone is composed by four different pistons. Piston 1 (pushing piston) is pneumatically driven and hydraulically coupled to piston 2 (driver piston), which is directly connected with the combustion chamber. Piston 3 is hydraulically driven and it can be adjusted to select the compression stroke. Finally, piston 4 contains the compressed air that drives the machine. Further details on the operation principle of the RCEM can be found in [29]. 


\begin{tabular}{|l|ll|}
\hline Bore & 84 & $\mathrm{~mm}$ \\
\hline Stroke & $120-249$ & $\mathrm{~mm}$ \\
\hline Compression ratio & $5-30$ & - \\
\hline Maximum cylinder pressure & 200 & bar \\
\hline Initial pressure & $1-5$ & bar \\
\hline Maximum heating temperature & 473 & $\mathrm{~K}$ \\
\hline
\end{tabular}

Table 1: Technical characteristics of the RCEM.

The technical characteristics of the RCEM can be seen in Table 1. The pushing piston and the driver piston are instrumented with two AMO LMK102 incremental position sensors $(0.01 \mathrm{~mm}$ of resolution), which allow knowing the absolute position of each piston and, therefore, the combustion chamber volume. The combustion chamber is composed by three elements: the experimentation piston (mechanically connected to the driver piston), the liner and the cylinder head. The experimentation piston consists of a steel-made piston with a $84 \mathrm{~mm}$ bore and a quartz-made bowl with cylindrical shape, $50 \mathrm{~mm}$ of bore and $2.2 \mathrm{~mm}$ in depth, which allows the axial optical access. As the bowl is flat, the chamber images can be recorded without any image distortion.

Besides, the cylinder head and the cylinder liner have different heating elements arranged in six separately controlled zones, which are responsible for heating the cylinder walls and the experimentation piston. The wall temperature is measured by a total of six K-type thermocouples, two located in the cylinder head and four in the liner. Very good temperature homogeneity has been observed [29], with a standard deviation in gas temperature of the 
order of $3 K$. It was found that the distribution of temperature is barely affected by the gas in-flow due to its low speed. An initial gas temperature equal to the wall temperature is achieved due to the long duration of the intake process.

The cylinder head is instrumented with a Kistler 7061B cooled piezoelectric pressure sensor $(-80 p C /$ bar of sensitivity), which is coupled to a Kistler 5011 charge amplifier, and whereby the in-cylinder pressure is measured. Different piezo-resistive pressure sensors are available to control the filling of the driving gas and of the combustion chamber (0.01bar of resolution). The injection system is composed by a Siemens hollow cone piezo-injector with a cone angle of $90^{\circ}$, which is centered in the cylinder head. Its fuel delivery rate has been previously measured with an IAV injection rate analyzer. The transient signals have been recorder at $100 \mathrm{kHz}$ with a PC-based transient measurement recorder. The RCEM is filled from an external tank that can be heated up to $373 K$. The synthetic air is produced in the tank by a filling based on partial pressures where $\mathrm{N}_{2}, \mathrm{CO}_{2}$ and $\mathrm{O}_{2}$ can be used. The mixture is analyzed in a Horiba PG-250 portable gas analyzer in order to know the exact composition and ensure the correct reproduction of the experiments in CHEMKIN.

The desired stroke of the machine is selected and the RCEM is heated up to the desired temperature. The synthetic air-EGR mixture is prepared in the mixing tank by a filling based on partial pressures. In this study, EGR was considered as the products of a complete combustion reaction between the fuel and dry air in which the amount of oxygen is the one desired by the user, as explained in [30]. The combustion chamber is scavenged several 
times before the filling. The fuel is injected into the combustion chamber at the start of the intake process to avoid problems of stratification or other inhomogeneities. The long duration of the process (approximately 40s), is enough to guarantee a homogeneous environment in the chamber when the compression stroke starts.

In order to ensure a representative ignition delay time measurement, the number of repetitions of each point has been selected so that the semiamplitude of the confidence interval with a level of confidence of $95 \%$ is smaller than $1 \%$ of the mean ignition delay value.

In this work the autoignition of the mixture is considered to be produced when the time derivative of the pressure signal (which will be referred as pressure rise rate further on) reaches a maximum. Thus, the ignition delay in the experimental facility is defined as the time between the start of the rapid compression process, which is a constant reference due to constructive aspects of the machine, and the instant in which the maximum pressure rise is obtained, as can be seen in Fig. 4. This way, cool flames and high temperature ignition delay can be easily distinguished in case of having twostage ignition.

Finally, the temperature profile is calculated for each experiment by applying the energy equation, since the pressure profile and the position of the piston are known. The heat losses are characterized by a model based on the Woschni correlation [31]. The calculation includes two additional models for deformations and leaks, both of them explained in [32, 33]. 


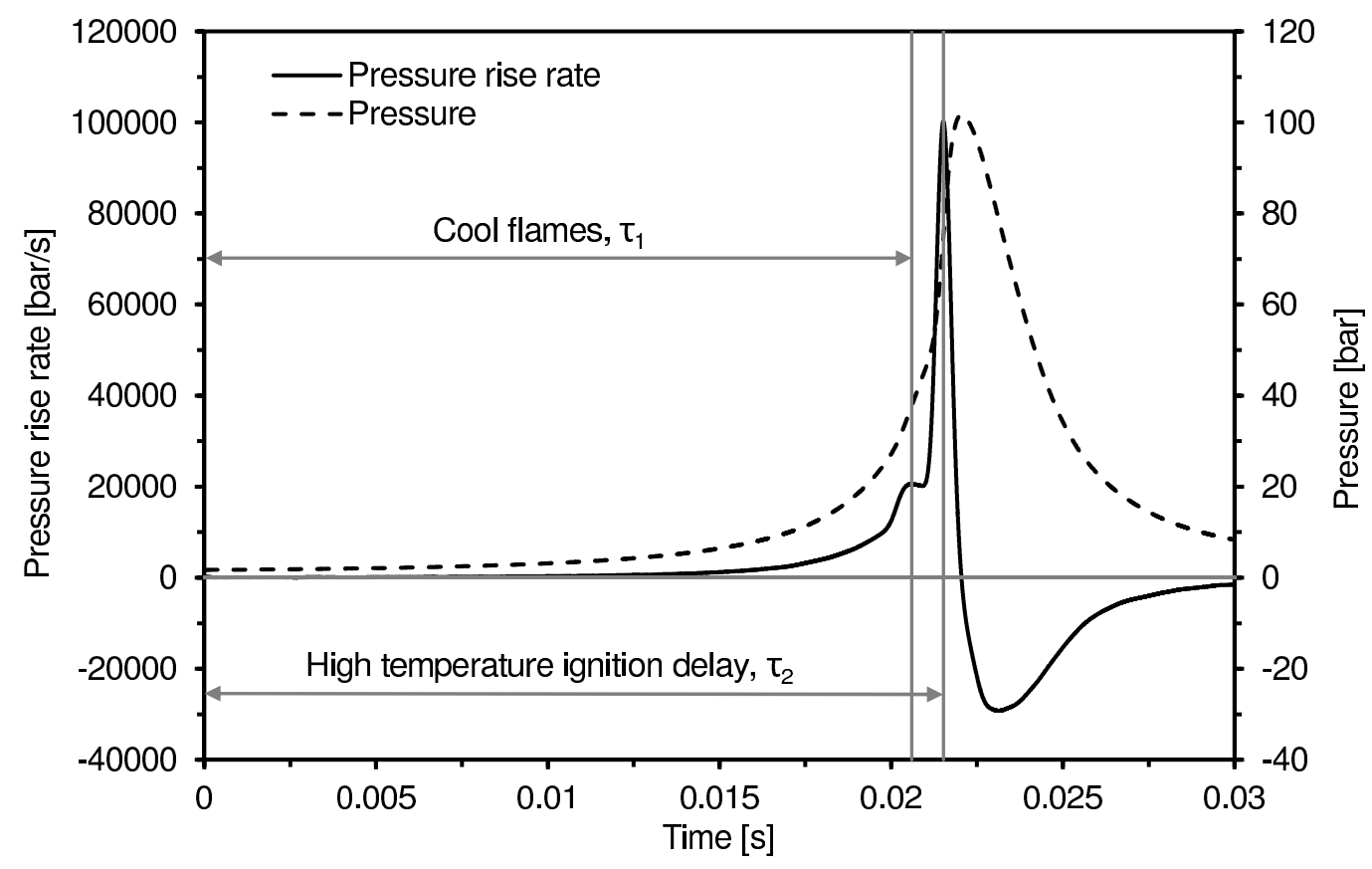

Figure 4: Ignition delay definition. The autoignition of the mixture is considered to be produced when the maximum pressure rise occurs. 


\subsection{CHEMKIN and chemical kinetic mechanisms}

CHEMKIN-PRO is the software used to obtain the different ignition delays and critical concentrations. The Curran's kinetic mechanism is used for $n$-heptane and iso-octane [34, 35]. This mechanism consists of 1034 species and 4238 reactions, and includes the chemical kinetics of the two hydrocarbons used in this investigation. Its validity has been checked in several articles $[22,36]$ by comparison with experimental results.

The model used to obtain ignition delays under constant conditions, $\tau_{C C}$, $\tau_{1}$ and $\tau_{2}$, and critical concentrations is a homogeneous closed reactor (perfectly stirred reactor, PSR), which works with constant pressure and uses the energy equation to solve the temperature temporal evolution. This model is the most appropriate to obtain ignition delays at constant pressure and temperature conditions [37].

The model used to obtain ignition delays under transient conditions is a reciprocating internal combustion engine operating with homogeneous charge (IC-engine, closed 0-D reactors from CHEMKIN). The volume profile as well as the heat loss profile are imposed in order to reproduce the RCEM conditions. The piston starts at bottom dead center (BDC) and a complete cycle of the RCEM is simulated. The autoignition is considered to be produced when the time derivative of the pressure signal reaches a maximum. This is the same criterion than the used in the experiments and, therefore, it allows comparing the simulated results directly with the experimental ones.

Finally, the ignition delays and the critical concentration are obtained for each thermodynamic state with a $\Delta t$ of $10^{-5} s$, which is the experimental resolution of the pressure signal. This value of the time step also represents 
an equilibrium between appropriate prediction accuracy and reasonable calculation time. Besides, the maximum waiting time for the autoignition of the mixture has been set to $30 \mathrm{~s}$.

\subsection{Parametric study performed}

The performed experimental study was as follows:

- Fuel: $n$-heptane and iso-octane.

- Initial temperature $\left(T_{i}\right)$ : $358 K$ (only for n-heptane), $383 K, 408 K$, $433 K$ and $458 K$.

- Initial pressure $\left(P_{i}\right): 0.14 M P a$ and $0.17 M P a$.

- Compression stroke: $249 \mathrm{~mm}$.

- Compression ratio $(C R): 15$ and 17 .

- Oxygen molar fraction $\left(\mathrm{X}_{\mathrm{O}_{2}}\right)$ : 0.21 (0\% EGR), 0.147 (30\% EGR), 0.126 (40\% EGR) and 0.105 (50\% EGR).

- Equivalence ratio $(F r)$ : from 0.3 to 0.8 depending on the fuel and on the oxygen mass fraction.

The maximum equivalence ratio is limited by the working oxygen molar fraction in order to avoid extremely violent combustions. The equivalence ratio of 0.4 has been chosen as base point in order to have the possibility to try leaner and richer mixtures without damaging the facility. The performed parametric study can be seen in Table 2. Finally, the temperature of the combustion chamber is always above the boiling point of the fuel, therefore ensuring that the fuel is in vapor phase before the beginning of the cycle. 


\begin{tabular}{|c|c|c|c|c|c|c|}
\hline & \multicolumn{5}{|c|}{$\mathbf{T}_{i}[\mathbf{K}]$} \\
\hline & & 358 & 383 & 408 & 433 & 458 \\
\hline \multirow{6}{*}{ Fr [-] } & 0.3 & 40 & & $0,30,40,50$ & & 40 \\
\hline & 0.4 & $0,30,40,50$ & 40,50 & $0,30,40,50$ & 40,50 & $\mathbf{0}, \mathbf{3 0}, 40,50$ \\
\hline & 0.5 & 40 & 40 & 40,50 & 40 & 40 \\
\hline & 0.6 & 40 & & 40,50 & & 40 \\
\hline & 0.7 & & & 40,50 & & \\
\hline & 0.8 & & & 40,50 & & \\
\hline
\end{tabular}

Table 2: Parametric study performed. EGR percent for different initial temperatures and equivalence ratios. Italic.- exclusively for n-heptane. Bold.- exclusively for iso-octane.

\section{Validation and results}

Ignition delays obtained solving the n-heptane and iso-octane detailed chemical kinetic mechanism are compared with the experimental results as a method to validate the mechanism in the desired range. Moreover, the experimental ignition delay is intended to be predicted by using not only the integral method presented in this paper (Eq. 3 and 5) but also the Livengood \& Wu integral method. Two different events have been studied front a point of view of the auto-ignition process: cool flames and the high exotermic stage of the ignition process.

\subsection{Predictive methods applied to cool flames}

Cool flames is a phenomenon only present in the cases performed with n-heptane. Ignition delays referred to cool flames are obtained experimentally and by direct chemical kinetic simulation in CHEMKIN. Besides, two different predictive methods have been evaluated. First, the integral method 
described by Eq. 3 has been used assuming $\mathrm{HO}_{2}$ as chain carrier. It is not necessary to evaluate Eq. 5, since no disappearance of chain carriers occurs at the same instant than cool flames. Finally, the Livengood \& Wu integral method (Eq. 1) has been applied by using a $\tau_{1}$ function referred to cool flames.

The percentage deviation in ignition delay, $\epsilon$, was calculated in order to compare more easily experimental and simulation results. This deviation is defined as follows:

$$
\epsilon=\frac{t_{i, 1 x}-t_{i, 1 R C E M}}{t_{i, 1 R C E M}} 100
$$

where $t_{i, 1}$ represents the time of ignition (ignition delay under transient conditions) referred to cool flames. The subscript $x$ can represent either data obtained from a chemical simulation with CHEMKIN using a closed 0-D IC-engine reactor, $I C E$, from the new predictive method, Int, or from the Livengood \& Wu integral method, $L W$. Finally, the subscript $R C E M$ represents data obtained experimentally from the RCEM.

The ignition delay deviations between the chemical kinetic simulations and the experimental results are shown in Fig. 5 for all cases that show a two-stage ignition pattern. The mean absolute deviation, $|\bar{\epsilon}|$, has been calculated and its value can be seen in the figure.

The results show that simulations are able to reproduce the experimental ignition delays with quite good accuracy. In fact, the confidence interval for the mean absolute deviation, $|\bar{\epsilon}|$, with a confidence level of $95 \%$ is equal to [1.331, 4.345]. Ignition delay deviations are caused partly by the chemical kinetic mechanism used and partly by the uncertainties in the calculation of 


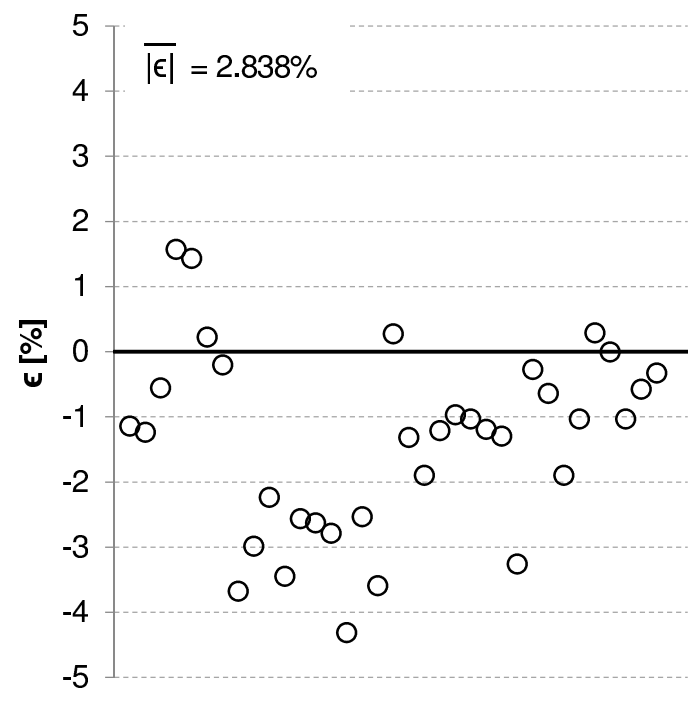

Figure 5: Percentage deviation in ignition delay. The mean absolute deviation, $|\bar{\epsilon}|$, shows good agreement between both experimental and simulated results.

the effective volume and the heat losses of the RCEM. It can be seen that the ignition delay referred to cool flames is underestimated by the mechanism. As Fig. 6 shows, this is mainly caused because of the higher pressure rise rate calculated by CHEMKIN. Despite the fact that cool flames start in both cases approximately at the same instant, the maximum pressure rise rate is reached much faster in the simulations, which leads to a certain deviation between these cases and the experiments. The absence of wall effects and heterogeneities in CHEMKIN causes a faster pressure rise not only in the case of cool flames, but also in the case of the high-temperature stage of the process.

The predicted ignition delays also show quite good agreement with the experimental results. The confidence intervals for $|\bar{\epsilon}|$ with a confidence level 


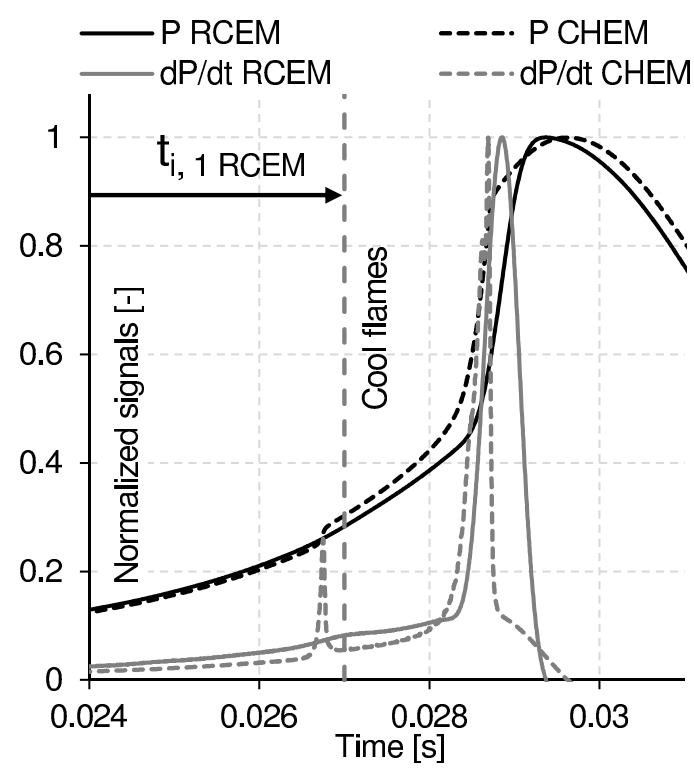

Figure 6: Pressure signal and pressure rise rate obtained experimentally and by simulation. $\mathrm{T}_{i}=408 K, \mathrm{P}_{i}=0.14 M P a, C R=15, \mathrm{X}_{O_{2}}=0.147, F r=0.4$, n-heptane. 
of $95 \%$ are summarized in Table 3 for the predictive methods. These values of $|\bar{\epsilon}|$ are very similar to each other, meaning that both predictive methods are able to predict the ignition delay referred to cool flames with the same accuracy than the detailed chemical kinetic mechanism.

\begin{tabular}{|r|c|}
\cline { 2 - 2 } \multicolumn{1}{c|}{} & n-Heptane \\
\hline CHEMKIN & {$[1.331,4.345] \%$} \\
\hline New integral proposed & {$[1.064,4.204] \%$} \\
\hline Livengood \& Wu & {$[1.066,4.155] \%$} \\
\hline
\end{tabular}

Table 3: Confidence interval for the mean absolute deviation referred to cool flames, $|\bar{\epsilon}|$, with a confidence level of $95 \%$ for the chemical kinetic simulations (CHEMKIN) and for the different predictive methods.

$\mathrm{HO}_{2}$ can be assumed as a good tracer of cool flames, since the time of ignition referred to a critical concentration of $\mathrm{HO}_{2}$ predicted by Eq. 3 shows good agreement with the time of ignition of cool flames. Moreover, it should be noted that the Livengood \& Wu integral method can be used to predict cool flames without assuming high deviations.

\subsection{Predictive methods applied to the high exothermic stage}

Ignition delays referred to a maximum pressure rise rate are obtained experimentally and by direct chemical kinetic simulations in CHEMKIN. Moreover, three different predictive methods have been evaluated now:

- The integral method described by Eq. 3 and Eq. 5 has been used, assuming $\mathrm{CH}_{2} \mathrm{O}$ as a chain carrier.

- The Livengood \& Wu integral method (Eq. 1) has been applied by using a $\tau_{2}$ function referred to a maximum pressure rise. 
- The alternative integral proposed by Hernandez et al. [19] has also been evaluated for the cases that show cool flames.

This last alternative method consists of solving the following two integrals:

$$
\begin{aligned}
& 1=\int_{0}^{t_{i, 1}} \frac{1}{\tau_{1}} d t \\
& 1=\int_{t_{i, 1}}^{t_{i, 2}} \frac{1}{\tau_{2}-\tau_{1}} d t
\end{aligned}
$$

where $t_{i, 1}$ and $\tau_{1}$ represents ignition delays referred to cool flames and $t_{i, 2}$ and $\tau_{2}$ represents ignition delays referred to the maximum pressure rise rate. Obviously, it is not possible to use this method with fuels that show a singlestage ignition, and therefore it has been evaluated only for n-heptane.

It should be noted that the new method proposed in this paper (Eq. 3 and 5 ) is a general method that can be used for all fuels, since the ignition delay referred to a critical concentration of chain carriers can be defined despite the absence of cool flames.

The percentage deviation in ignition delay, $\epsilon$, was calculated in order to compare more easily experimental and simulation results. This deviation is defined as follows:

$$
\epsilon=\frac{t_{i, 2 x}-t_{i, 2 R C E M}}{t_{i, 2 R C E M}} 100
$$

where $t_{i, 2}$ represents the time of ignition (ignition delay under transient conditions) referred to a maximum pressure rise rate. The subscript $x$ can represent either data obtained from a chemical simulation with CHEMKIN using 


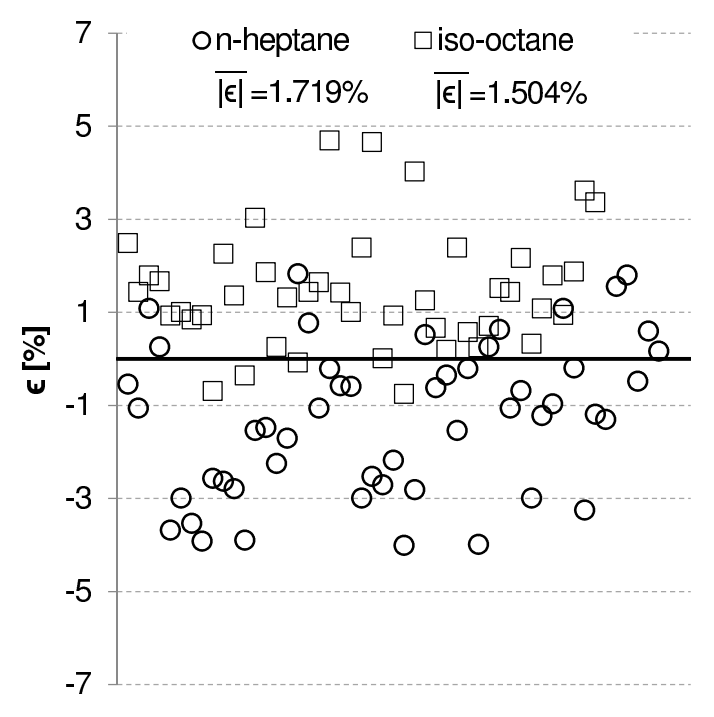

Figure 7: Percentage deviation in ignition delay. The mean absolute deviation, $|\bar{\epsilon}|$, shows a good agreement between both experimental and simulated results.

a closed 0-D IC-engine reactor, ICE, from the new predictive method, Int, from the Livengood \& Wu integral method, $L W$, or from the alternative method proposed by Hernandez, $L W-\bmod$. Finally, the subscript $R C E M$ represents data obtained experimentally from the RCEM.

The ignition delay deviations between the chemical kinetic simulations and the experimental results are shown in Fig. 7 for all cases. The mean absolute deviation, $|\bar{\epsilon}|$, has been calculated and its value can be seen in the figure.

The results show that simulations are able to reproduce the experimental ignition delays with quite good accuracy. In fact, the confidence interval for the mean absolute deviation, $|\bar{\epsilon}|$, with a confidence level of $95 \%$ is equal to $[1.331,1.984]$ for $n$-heptane and equal to $[1.213,1.894]$ for iso-octane. As 
before, ignition delay deviations are caused partly by the chemical kinetic mechanism used and partly by the uncertainties in the calculation of the effective volume and the heat losses in the RCEM. It can be seen that the ignition delay referred to a maximum pressure rise is underestimated for nheptane but overestimated for iso-octane. As explained in [24], this fact is probably because the rates of alkyl-peroxyl radical isomerization and peroxyalkylhydroperoxyl radical isomerization have been decreased by a factor of three compared to n-heptane in the case of the iso-octane sub-mechanism.

The confidence intervals for $|\bar{\epsilon}|$ with a confidence level of $95 \%$ are summarized in Table 4 for all the predictive methods. The new integral method proposed in this paper shows good agreement with the experiments. However, the accuracy of the Livengood \& Wu integral method shows a strong dependence on the type of fuel. It can be seen that the Livengood \& Wu integral is able to predict accurately the ignition delay referred to the high exothermic stage of combustion if the fuel shows a single-stage ignition (iso-octane), but the predictive capability is significantly reduced when a two-stage ignition occurs (n-heptane). Finally, the method proposed by Hernandez et al. shows poor predictive capability, but better results than the Livengood \& $\mathrm{Wu}$ integral.

The Livengood \& Wu predictive method assumes that autoignition occurs when a critical concentration of chain carriers is reached. Therefore, only ignition delays referred to a critical concentration can be predicted, which occur at a different stage than the maximum pressure rise rate. Moreover, only information referred to a critical concentration of chain carriers, $\tau$, should be used in the integral by definition of the method itself. These facts cause 


\begin{tabular}{|r|c|c|}
\cline { 2 - 3 } \multicolumn{1}{c|}{} & n-Heptane & iso-Octane \\
\hline CHEMKIN & {$[1.331,1.984] \%$} & {$[1.213,1.894] \%$} \\
\hline New integral proposed & {$[1.751,3.686] \%$} & {$[0.907,1.817] \%$} \\
\hline Livengood \& Wu & {$[5.894,14.354] \%$} & {$[0.898,1.855] \%$} \\
\hline Hernandez et al. & {$[5.623,11.778] \%$} & - \\
\hline
\end{tabular}

Table 4: Confidence interval for the mean absolute deviation referred to a maximum pressure rise, $|\bar{\epsilon}|$, with a confidence level of $95 \%$ for the chemical kinetic simulations (CHEMKIN) and for the different predictive methods.

an intrinsic deviation between predictions and experimental results, which leads to unacceptable predictions for fuels that show cool flames. It should be noted that if the fuel does not present a two-stage ignition pattern or if it presents a very smooth (or inexistent) NTC zone, the different ignition delays are virtually the same and the Livengood \& Wu integral method can predict ignition delays with high accuracy.

\section{Conclusions}

In this work a new method to predict ignition delays under transient conditions from those obtained under constant conditions is developed. The method allows to obtain not only the ignition delay referred to cool flames but also the time of ignition referred to a critical concentration of chain carriers and referred to a maximum pressure rise rate. Finally, this new method shows better results than the Livengood \& Wu integral method.

A detailed chemical kinetic mechanism has been validated in the working range versus experimental results obtained from a RCEM. Besides, the new 
predictive method and the Livengood \& Wu integral have also been compared to the experiments.

The following conclusions can be deduced from this study:

- Cool flames can be accurately reproduced with all the predictive methods used in this paper, since the critical concentration of $\mathrm{HO}_{2}$ occurs at the same instant than the maximum pressure rise associated to this phenomenon. Thus, $\mathrm{HO}_{2}$ can be assumed as a cool flames tracer.

- The new integral method proposed by the authors has shown a good predictive capability related with ignition delays referred to a maximum pressure rise rate. Therefore, the predicted ignition delays can be easily measured experimentally. Moreover, the new integral method does not depend on the existence of cool flames, since it can be applied for all type of fuels.

- The Livengood \& Wu integral method is able to predict ignition delays referred to the high exothermic stage of combustion only if the fuel shows a single-stage ignition. This method is originally based on the premise that autoignition occurs when the critical concentration of chain carriers is reached. Therefore, the predicted ignition delays will be referred to this criterion and the information used to obtain the predictions may be also referred to this criterion. Otherwise, an intrinsic deviation between predictions obtained from the Livengood \& $\mathrm{Wu}$ integral and the experimental results appears, since both ignition delays could be referred to different stages of the combustion process. If the fuel does not present a two-stage combustion or if the NTC zone is 
very soft, all criteria to define the ignition delay are virtually the same and they can be compared with each other. Thus, the Livengood \& $\mathrm{Wu}$ integral can be used with high accuracy to predict ignition delays of single-stage ignition fuels but not with fuels that show a two-stage ignition pattern. 


$\begin{array}{ll}B D C & \text { Bottom Dead Center } \\ C C & \text { Chain carriers } \\ C F D & \text { Computational Fluid Dynamics } \\ C I & \text { Compression Ignition } \\ C R & \text { Compression Ratio } \\ E G R & \text { Exhaust Gas Recirculation } \\ \text { Fr } & \text { Working equivalence ratio } \\ H C C I & \text { Homogeneous Charge Compression Ignition } \\ I C E & \text { Referred to data obtained from CHEMKIN using the internal } \\ & \text { combustion engine reactor } \\ \text { Int } & \text { Referred to data obtained from the new integral proposed in }\end{array}$


LW Referred to data obtained from the Livengood \& Wu integral method

$L W-\bmod$ Referred to data obtained from the predictive method proposed by Hernandez et al. [19]

LTC Low Temperature Combustion

$\max \quad$ Referred to a maximum concentration of chain carriers

NTC Negative Temperature Coefficient

$P_{i} \quad$ Initial pressure

PCCI Premixed Charge Compression Ignition

PRF Primary Reference Fuels

$P S R \quad$ Perfectly Stirred Reactor

RCCI Reactivity Controlled Compression Ignition

RCEM Rapid Compression-Expansion Machine

SI Spark Ignition

$T_{i} \quad$ Initial temperature

TDC Top Dead Center

$t_{i} \quad$ Ignition delay under transient conditions

$t_{i, C C} \quad$ Ignition delay referred to the critical concentration of chain carriers

$t_{i, 1} \quad$ Ignition delay referred to the maximum pressure rise of cool flames

$t_{i, 2} \quad$ Ignition delay referred to the maximum pressure rise

UHC Unburned hydrocarbons 


$\begin{array}{ll}X_{O 2} & \text { Oxygen molar fraction } \\ \epsilon & \text { Percentage deviation in ignition delay between experimental } \\ & \text { and simulation or predcited results } \\ & \text { Mean absolute deviation between experimental and simula- } \\ & \text { tion or predicted results } \\ & \text { Ignition delay under constant conditions of pressure and tem- } \\ & \text { perature } \\ \tau_{C C} & \text { Ignition delay under constant thermodynamic conditions re- } \\ & \text { ferred to the critical concentration of chain carriers } \\ \tau_{1} & \text { Ignition delay under constant thermodynamic conditions re- } \\ & \text { ferred to the maximum pressure rise of cool flames } \\ \tau_{2} & \text { Ignition delay under constant thermodynamic conditions re- } \\ & \text { ferred to the maximum pressure rise }\end{array}$

\section{Appendix A. Theoretical development of a new expression to pre-} dict high-temperature ignition delays

Ignition delays referred to a maximum pressure rise occur after the crit- 


$$
1=\frac{1}{[C C]_{\max , t_{i, C C}}} \int_{0}^{t_{i, C C}} \frac{[C C]_{\max }}{\tau_{C C}} d t
$$

where $t_{i, C C}$ is the ignition delay of the process referred to a maximum concentration of chain carriers, and $\tau_{C C}$ and $[C C]_{\max }$ are the ignition delay referred to a maximum of chain carriers and the critical concentration of chain carriers, respectively, under constant conditions of pressure and temperature for the successive thermodynamic states.

Therefore, it is possible to study the decomposition of chain carriers from $\mathrm{t}_{i, C C}$ and, thus, to obtain the ignition delay under transient thermodynamic conditions referred to the maximum pressure rise rate, $t_{i, 2}$.

Starting from the Glassman's model for autoignition [38], the global disappearance rate of chain carriers, $[C C]$, can be written as:

$$
\frac{d[C C]}{d t}=k_{1}[R]+\left(\left(k_{2}(\alpha-1)-k_{4}\right)[R]-k_{5}\right)[C C]
$$

where $[R]$ represents the fuel, $\alpha$ is a multiplicative factor that represents the chain behavior of $[C C]$ and $k_{1}, k_{2}, k_{4}$ and $k_{5}$ represent the specific reaction rate of the initiation reaction, the chain reaction, the main termination reaction and the termination reaction by wall effects, respectively.

Taking into account that the termination reactions are dominant after reaching the critical concentration of chain carriers, the previous equation can be written as:

$$
\frac{d[C C]}{d t}=-\left(k_{4}[R]+k_{5}\right)[C C]=-A[C C]
$$


where A depends on specific reaction rates and on the fuel concentration.

Assuming a process under constant conditions of pressure and temperature during the ignition delay, and assuming that $[R] \gg[C C]$, Eq. A.3 can be integrated with the condition $[C C]=[C C]_{\max }$ when $t=\tau_{C C}$ (ignition delay under constant thermodynamic conditions referred to a critical concentration) as follows:

$$
\frac{[C C]}{[C C]_{\max }}=\exp \left(A\left(\tau_{C C}-t\right)\right)
$$

The exponential term in Eq. A.4 can be approximated by a Taylor series expansion that can be truncated in the second term, resulting in the following expresion:

$$
\frac{[C C]}{[C C]_{\max }}=1+A\left(\tau_{C C}-t\right)
$$

taking into account the condition $[C C]=0$ when $t=\tau_{2}$ (ignition delay under constant thermodynamic conditions referred to a maximum pressure rise), the folowing expresion can be finally obtained for the evolution of chain carriers:

$$
\frac{[C C]}{[C C]_{\max }}=\frac{\tau_{2}-t}{\tau_{2}-\tau_{C C}}
$$

equation that is only valid under constant conditions of pressure and temperature, since otherwise Eq. A.3 cannot be integrated.

If a process under transient thermodynamic conditions is discretized as a series of thermodynamic states that remain constant for a time $d t$, the ignition time can be obtained by discretizing Eq. A.6 as follows: 


$$
\frac{d[C C]}{[C C]_{\max }}=-\frac{d t}{\tau_{2}-\tau_{C C}}
$$

and integrating it during the period of time between the critical concentration of chain carriers and the maximum heat release rate:

$\int_{[C C]_{\max , t_{i, C C}}^{0}}^{0} d[C C]=-\int_{t_{i, C C}}^{t_{i, 2}} \frac{[C C]_{\max }}{\tau_{2}-\tau_{C C}} d t \rightarrow 1=\frac{1}{[C C]_{\max , t_{i, C C}}} \int_{t_{i, C C}}^{t_{i, 2}} \frac{[C C]_{\max }}{\tau_{2}-\tau_{C C}} d t$

where $t_{i, 2}$ is the ignition delay of the process referred to a maximum heat release rate, and $\tau_{C C}, \tau_{2}$ and $[C C]_{\max }$ are the ignition delay referred to a maximum of chain carriers, the ignition delay referred to the high exothermic stage and the critical concentration of chain carriers under constant conditions of pressure and temperature for the successive thermodynamic states, respectively.

It should be noted that Eq. A.8 can be combined with Eq. A.1 to predict both ignition delays referred to a critical concentration and, starting from it, the one referred to a maximum pressure rise rate.

\section{References}

[1] J. Benajes, S. Molina, A. García, and J. Monsalve-Serrano. Effects of direct injection timing and blending ratio on RCCI combustion with different low reactivity fuels. Energy Conversion and Management, 99:193209, 2015. 
[2] Z. Zheng, L. Yue, H. Liu, Y. Zhu, X. Zhong, and M-Yao. Effect of two-stage injection on combustion and emissions under high EGR rate on a diesel engine by fueling blends of diesel/gasoline, diesel/n-butanol, diesel/gasoline/n-butanol and pure diesel. Energy Conversion and Management, 90:1-11, 2015.

[3] T. Li, D. Wu, and M. Xu. Thermodynamic analysis of EGR effects on the first and second law efficiencies of a boosted spark-ignited directinjection gasoline engine. Energy Conversion and Management, 70:130138, 2013.

[4] J. Benajes, J.V. Pastor, A. García, and J. Monsalve-Serrano. An experimental investigation on the influence of piston bowl geometry on RCCI performance and emissions in a heavy-duty engine. Energy Conversion and Management, 103:1019-1030, 2015.

[5] S.S. Nathan, J.M. Mallikarjuna, and A. Ramesh. An experimental study of the biogas-diesel HCCI mode of engine operation. Energy Conversion and Management, 51:1347-1353, 2010.

[6] K. Bahlouli, U. Atikol, R.K. Saray, and V. Mohammadi. A reduced mechanism for predicting the ignition timing of a fuel blend of naturalgas and n-heptane in HCCI engine. Energy Conversion and Management, 79:85-96, 2014.

[7] J.C. Livengood and P.C. Wu. Correlation of autoignition phenomena in internal combustion engines and rapid compression machines. Symposium (International) on Combustion, 5:347-356, 1955. 
[8] L. Chen, T. Li, T. Yin, and B. Zheng. A predictive model for knock onset in spark-ignition engines with cooled EGR. Energy Conversion and Management, 87:946-955, 2014.

[9] M. Shahbakhti, R. Lupul, and C. R. Koch. Predicting HCCI autoignition timing by extending a modified knock-integral method. $S A E$ Paper no. 2007-01-0222, 2007.

[10] Y. Ohyama. Engine control using a combustion model. Seoul 2000 FISITA World Automotive Congress, 2000.

[11] D.J. Rausen, A.G. Stefanopoulou, J.M. Kang, J.A. Eng, and T.W. Kuo. A mean-value model for control of homogeneous charge compression ignition HCCI engines. Journal of Dynamic Systems, Measurement, and Control, 127:355-362, 2005.

[12] Y. Choi and J.Y. Chen. Fast prediction of start-of-combustion in HCCI with combined artificial neural networks and ignition delay model. Proceedings of the Combustion Institute, 30:2711-2718, 2005.

[13] M. Hillion, J. Chauvin, and N. Petit. Control of highly diluted combustion in diesel engines. Control Engineering Practice, 19:1274-1286, 2011.

[14] Y. Imamori, H. Endo, K. Sakaguchi, and J. Yanagi. Development of combustion system in low speed two-stroke diesel engine using CFD. International Council on Combustion Engines, 2004.

[15] G. Li, T. Bo, C. Chen, and R.J.R. Johns. CFD simulation of HCCI 
combustion in a 2-stroke DI gasoline engine. SAE Paper no. 2003-01$1855,2003$.

[16] A.D.B. Yates, A. Swarts, and C.L. Viljoen. Correlating auto-ignition delays and knock-limited spark-advance data for different types of fuel. SAE Paper no. 2005-01-2083, 2005.

[17] L. Liang and R.D. Reitz. Spark ignition engine combustion modeling using a level set method with detailed chemistry. SAE Paper no. 200601-0243, 2006.

[18] R. Edenhofer, K. Lucka, and H. Kohne. Low temperature oxidation of diesel-air mixtures at atmospheric pressure. Proceedings of the Combustion Institute, 31:2947-2954, 2007.

[19] J.J. Hernandez, M. Lapuerta, and J. Sanz-Argent. Autoignition prediction capability of the Livengood-Wu correlation applied to fuels of commercial interest. International Journal of Engine Research, 15:817$829,2014$.

[20] J. M. Desantes, J. J. López, S. Molina, and D. López-Pintor. Validity of the Livengood \& Wu correlation and theoretical development of an alternative procedure to predict ignition delays under variable thermodynamic conditions. Energy Conversion and Management, 105:836-847, 2015.

[21] J. M. Desantes, J. J. López, S. Molina, and D. López-Pintor. Theoretical development of a new procedure to predict ignition delays under transient thermodynamic conditions and validation using a Rapid 
Compression-Expansion Machine. Energy Conversion and Management, 108:132-143, 2016.

[22] M. Sjoberg and J.E. Dec. An investigation into lowest acceptable combustion temperatures for hydrocarbon fuel in HCCI engines. Proceedings of the Combustion Institute, 30:2719-2726, 2005.

[23] B. Baeuerle, J. Warnatz, and F. Behrendt. Time-resolved investigation of hot spots in the end gas of an S.I. engine by means of 2-D doublepulse LIF of formaldehyde. Symposium (International) on Combustion, 2:2619-26256, 1996.

[24] J. M. Desantes, J.M. García-Oliver, W. Vera-Tudela, D. López-Pintor, B. Schneider, and K. Boulouchos. Study of ignition delay time and generalization of auto-ignition for PRFs in a RCEM by means of natural chemiluminescence. Energy Conversion and Management, 111:217-228, 2016.

[25] G. Barroso, A. Escher, and K. Boulouchos. Experimental and numerical investigations on HCCI combustion. SAE Paper no. 2005-24-038, 2005.

[26] D. Mitakos, C. Blomberg, A. Vandersickel, Y. Wright, B. Schneider, and K. Boulouchos. Ignition delays of different homogeneous fuel-air mixtures in a Rapid Compression Expansion Machine and comparison with a 3 -stage-ignition model parametrized on shock tube data. $S A E$ Paper no. 2013-01-2625, 2013.

[27] S. Schlatter, B. Schneider, Y. Wright, and K. Boulouchos. Comparative study of ignition systems for lean burn gas engines in an optically 
accessible Rapid Compression Expansion Machine. SAE Paper no. 201324-0112, 2013.

[28] T. Steinhilber and T. Sattelmayer. The effect of water addition on HCCI diesel combustion. SAE Paper no. 2006-01-3321, 2006.

[29] S. Schlatter, B. Schneider, Y. Wright, and K. Boulouchos. Experimental study of ignition and combustion characteristics of a diesel pilot spray in a lean premixed methane/air charge using a Rapid Compression Expansion Machine. SAE Paper no. 2012-01-0825, 2012.

[30] J. M. Desantes, J. J. López, S. Molina, and D. López-Pintor. Design of synthetic EGR and simulation study of the effect of simplified formulations on the ignition delay of isooctane and n-heptane. Energy Conversion and Management, 96:521-531, 2015.

[31] G. Woschni. A universally applicable equation for the instantaneous heat transfer coefficient in the internal combustion engine. SAE Paper no. 670931, 1967.

[32] J. Benajes, P. Olmeda, J. Martín, and R. Carreño. A new methodology for uncertainties characterization in combustion diagnosis and thermodynamic modelling. Applied Thermal Engineering, 71:389-399, 2014.

[33] F. Payri, S. Molina, J. Martín, and O. Armas. Influence of measurement errors and estimated parameters on combustion diagnosis. Applied Thermal Engineering, 26:226-236, 2006. 
[34] H.J. Curran, P. Gaffuri, Pitz W.J, and C.K. Westbrook. A comprehensive modeling study of n-heptane oxidation. Combustion and Flame, 114:149-177, 1998.

[35] H.J. Curran, P. Gaffuri, Pitz W.J, and C.K. Westbrook. A comprehensive modeling study of iso-octane oxidation. Combustion and Flame, 129:253-280, 2002.

[36] H.J. Curran, W.J. Pitz, C.K. Westbrook, C.V. Callahan, and F.L. Dryer. Oxidation of automotive primary reference fuels at elevated pressures. Proceedings of the Combustion Institute, 27:379-387, 1998.

[37] F. Payri, X. Margot, S. Patouna, F. Ravet, and M. Funk. Use of a single-zone thermodynamic model with detailed chemistry to study a natural gas fueled Homogeneous Charge Compression Ignition engine. Energy Conversion and Management, 53:298-304, 2012.

[38] I. Glassman and R.A. Yetter. Combustion. Elsevier Academic Press, 2008. 